\title{
УДК 004.054.53
}

\section{ПРИМЕНЕНИЕ ИНТЕЛЛЕКТУАЛЬНЫХ ТЕХНОЛОГИЙ В ЭЛЕКТРОННОМ ДОКУМЕНТООБОРОТЕ}

\author{
Фархуллина Лилиана Гаязовна \\ студент \\ ФГБОУ ВО Нефтекамский филиал \\ «Башкирский государственный университет» \\ Миронова Наталия Геннадьевна
} к.филос.н.

ФГБОУ ВО «Башкирский государственный университет»

Аннотация: В статье рассматривается применение искусственного интеллекта в СЭД, описаны принципы применения данной технологии и затронута проблема безопасности в СЭД.

Ключевые слова: система электронного документооборота (СЭД), искусственный интеллект, безопасность СЭД, машинное обучение.

\section{APPLICATION OF INTELLECTUAL TECHNOLOGIES IN ELECTRONIC DOCUMENT MANAGEMENT}

\section{Farkhullina L.G. Mironova N.G.}

Abstract: the article discusses the use of artificial intelligence in the EDMS. The principles of application are described and the problem of security in the EDMS is touched upon.

Key words: electronic document management system (EDMS), artificial intelligence, EDMS security, machine learning.

Пандемия повысила заинтересованность многих организаций в развитии СЭД и ЕСМ-решений. Это связано с такими вызовами, как необходимость наладить и сохранить непрерывность процессов, безопасность сотрудников, управляемость IT-систем, избежать риска потери контроля. Для разрешения 


\section{СОВРЕМЕННЫЕ ТЕХНОЛОГИИ:

данных проблем актуальным вариантом будет использование СЭД в организации. Наиболее актуальны такие СЭД, в которых есть мобильное решение, инструменты электронной подписи и готовые интеграционные механизмы. В СЭД все чаще используются такие решения, как API/веб-сервисы, обмен стандартизованными XML, роботизация типовых операций переноса данных, искусственный интеллект для структурирования данных. [1]

Искусственный интеллект становится востребованным при автоматизации рутинных задач в документообороте организаций, в управлении информационным корпоративным контентом, при управлении бизнесом и производством (для прогнозирования спроса, планировании запасов, управлении рисками, управление оборудованием и технологическими процессами, прогнозировании рыночных цен, контроле качества, оптимизации бизнес-модели); интеллектуальные инструменты применяются в работе органов муниципального управления, в деятельности министерств и ведомств; инструменты на основе глубокого машинного обучения внедряются в медицине (для сбора и анализа данных, генерации контента, диагностики и терапии). Сферы и отрасли, где находит применение искусственный интеллект: промышленность (автоматизация технологических процессов), финансы (прогнозирование и анализ рисков, банкинг, биржевые операции), масс-медиа, медицина, решение задач бизнеса, таргетирование рекламы, рекомендательные системы, машинное зрение (например, при интеллектуальном распознании документов), распознание речи (автоматическая генерация документов с голоса), прогнозная аналитика и принятие решений (в т.ч. на основе электронных документов и иного электронного контента), безопасность (ИИ-технологии используются для анализа и идентификации угроз информационной безопасности, для снижения риска утечки конфиденциальной информации, в т.к. в системах электронного документооборота). [2] Системы автоматизации решения задач информационной безопасности с использованием технологий предиктивной аналитики и поведенческого анализа способны прогнозировать рискованное для организаций поведение персонала или злоумышленников, вектора кибератак и проч. Интеллектуальные функции поддерживают системы нового поколения таких классов, как SIEM, DLP (например, Traffic Monitor, «Гарда Предприятие» - интеллектуальная системы защиты от утечек информации), DPI-системы, IDS и IPS-системы (например, 


\section{СОВРЕМЕННЫЕ ТЕХНОЛОГИИ:

Snort, Tripwire, IBM ISS, McAfee, нейросетевая система обнаружения атак AUBAD и др.). В основе подобных систем могут быть заложены те или иные интеллектуальные технологии (нейросетевые модели, модели знаний, искусственные иммунные системы и генетические алгоритмы и т.д.). В целях повышения безопасности применения интеллектуальных технологий и обеспечения правовой среды в 2020 г. утверждена программа по созданию в РФ стандартов технологии искусственного интеллекта на 2021-2024 гг., включая стандарты безопасности применения ИИ в транспорте, медицине, образование, строительство, стандарта «Умное производство» и др.

Одна из областей, где интеллектуальные из таких применений искусственного интеллекта является автоматизация регистрации поступающей корреспонденции. Принцип работы данной системы заключается в том, что происходит анализ текста файла, выделение в нем ключевых сущностей, то есть выделение отправителя, подписанта, получателя, связанные документы и другие детали, а так же определение числа страниц документа. Из данной информации система формирует карточку документа с вложением и заполненными реквизитами. Умение искусственного интеллекта распознавать и анализировать текст позволяет регистрировать бумажный по аналогии с электронным документом. Вторым применением искусственного интеллекта в СЭД является проверка связей между документами. Искусственный интеллект анализирует содержание текста, определяя упоминание других документов, и автоматически устанавливает с ними связи. Данная технология способна значительно уменьшить количество ошибок, связанное с человеческим фактором. Третье применение искусственного интеллекта в СЭД - это автокатегоризация и тематическое тегирование документов. Данная технология позволяет категорировать документ в соответствии с принятой в организации классификацией. Применение этой технологии способно снизить трудоемкость оформления документа на входе, облегчить поиск документа и дальнейшую его автоматизированную обработку. Определение смысловых тегов документа позволяет организовать дальнейшую автоматическую обработку документа, которая включает в себя маршрутизацию на исполнителей, формирование подборок документов для выгрузок в другие системы, выделение определенных подпотоков для последующего анализа. И на данном этапе стоит отметить применение алгоритмов нейронных сетей, заданные с помощью ML-функций, в определении исполнителя и маршрутизации документов. Автоматическое 


\section{СОВРЕМЕННЫЕ ТЕХНОЛОГИИ:

определение исполнителя применяет математическую модель, обученная на данных о маршрутизации ранее поступивших документов. Автоматическое доведение определённых документов до инициаторов запросов совершает это мгновенно и снижается риски появления ошибок. Данная технология сможет не только ускорить процесс доведения документов, но и избежать этапы их рассмотрения. Настройка механизма автодоведения документа до исполнителя на основе тематического тегирования может автоматизировать работу других входящих документов. Для реализации данного механизма требуется создание справочника тем и функций организации с указанием ответственных подразделений или лиц. Данная система автоматически будет формировать резолюцию на исполнителей указанных тегов, определив тематический тег. Четвертый способ применения искусственного интеллекта в СЭД - это помощь в принятии решений и подготовке ответа. Данная технология позволяет выделить в тексте документа сущности и собрать по ним дополнительную информацию. C помощью ML-методов проводится анализ текста на основании собранной информации. Происходит распознавание сущностей, определение их классов, выделение их в тексте разными маркерами. Сущностями в данном случае являются контрагент, подразделение, связанные документы. На основе выявленных тематических тегов, для документа определяются используемые шаблоны ответов и формулировки, которые получает исполнитель вместе с заданием. Пятый способ применения искусственного интеллекта является автоматическое определение маршрута согласования. Данная технология оптимизирует согласование документов, а так же осуществляет проверку его правильности на основе семантического анализа и анализа ретроспективных данных о похожих документах. Таким образом, автоматизация рутинных действий снизит трудоемкость и повысит скорость обработки и других действий с документами, а также сократит время на учетно-оформительские операции в СЭД [3].

Стоит отметить, что СЭД позволяет визуализировать данные о действиях пользователей внутри системы, аналитику по исполнительской дисциплине, сводную информацию по количеству обработанных документов. И, конечно, существуют и другие проблемы в СЭД. Одна из таких проблем связана с хранением электронных документов. Выступает угрозой для СЭД отсутствие надежных технологий хранения, а так же уровень безопасности обеспечения данной технологией документов. Одним из решений безопасности СЭД может 


\section{СОВРЕМЕННЫЕ ТЕХНОЛОГИИ:

стать защита информации от несанкционированного доступа в систему, с помощью уникальной маркировки документов. Уникальная маркировка не предотвращает утечку данных, но с высокой точностью можно установить участок утечки данных. Для безопасности СЭД должны применяться методы криптографии: шифрование документов, шифрование каналов передачи данных с использованием различных протоколов (TLS, VPN), аутентификация пользователей c использованием строгих криптографических методов, электронная подпись [4]. Так же возможно применение искусственного интеллекта для обеспечения безопасности СЭД. Это может быть мониторинг пользователя в системе, определение подозрительных действий или проверка поступающего подозрительного трафика со стороны пользователя. Для этого можно применить алгоритмы машинного обучения, которые в свою очередь могут заменить взаимодействия с системами DPI.

Таким образом, искусственный интеллект имеет широкую область применения в СЭД. Она позволяет автоматизировать многие задачи, снижает риски появления ошибок, связанные с человеческим фактором, и оптимизацию многих других задач. Стоит отметить то, что применение искусственного интеллекта возможно для обеспечения безопасности СЭД с помощью ML-методов.

\section{Список литературы}

1. Лекцию о развитии СЭД/ЕСМ-решений в контексте комплексной цифровизации представила компания ЭОС на вебинаре РАНХиГС [Электронный pecypc]: eos.ru. - 2021 - Режим доступа: https://eos.ru/eos_about/ eos_news/detail.php?ID=31321 - (Дата обращения: 15.10.2021).

2. Миронова Н.Г. Глава 5. Безопасность использования когнитивных информационных технологий принятия решений // Экономика и право: монография / В.В. Арбекова, Ю.А. Быченок, М.Л. Вартанова, А.В. Григорищин, Е.Н. Иванова, Л.А. Костыгова, В. Н. Круглов, Н.Г. Миронова и др. / гл. ред. Э.В. Фомин. - Чебоксары: ИД «Среда», 2021. - 184 с. - URL: https:// www.elibrary.ru/download/elibrary_46291292_50473306.pdf $\quad$ (DOI: 10.31483/r98432) - С. 117-119. - (Дата обращения: 28.10.2021).

3. Как искусственный интеллект помогает оптимизировать работу госсектора в СЭД [Электронный pecypc]: it-world.ru. - 2021 - Режим доступа: https://www.it-world.ru/cionews/business/178752.html - (Дата обращения: 28.10.2021). 


\section{СОВРЕМЕННЫЕ ТЕХНОЛОГИИ: \\ ТЕНДЕНЦИИ И ПЕРСПЕКТИВЫ РАЗВИТИЯ}

4. Защищенный документооборот [Электронный pecypc]: rutoken.ru. Режим доступа: https://www.rutoken.ru/technologies/using/docflow/ - (Дата обращения: 03.10.2021).

(C) Н.Г. Миронова, Л.Г. Фархуллина, 2021 